\title{
Dose Response and FWHM Properties of Dyed Poly Vinyl Alcohol-Irradiated with Gamma-Rays
}

\author{
Mohamad El-Saied El-Nagdy ${ }^{1}$, Mohamad Rabeaa El-Saadany ${ }^{1,2}$, Antar El-Saied Mohamad ${ }^{3}$ \\ ${ }^{1}$ Department of Physics, Faculty of Science, Helwan University, Cairo, Egypt \\ ${ }^{2}$ Al Kasr Al Aini Hospitals, Critical Care-Gamma Camera Lab Technology, Cairo, Egypt \\ ${ }^{3}$ National Center for Radiation Research Technology, Cairo, Egypt \\ Email: anter_protect@yahoo.com
}

Received March 11, 2013; revised April 14, 2013; accepted April 20, 2013

Copyright (C) 2013 Mohamad El-Saied El-Nagdy et al. This is an open access article distributed under the Creative Commons Attribution License, which permits unrestricted use, distribution, and reproduction in any medium, provided the original work is properly cited.

\begin{abstract}
The effects of gamma irradiation on absorption properties of Carbol Fuchsin (CF) with crystal violet dyed Poly Vinyl Alcohol (PVA) blended for possible use in dosimetry and measurement of radiation dose in gamma rays have been studied using UV-Visible spectrophotometer method. The films were irradiated to accumulated doses from (10 to 70) Gy using $\mathrm{Co}^{60}$ gamma ray source at a constant dose rate. The absorption spectra were measured using UV-Visible spectrophotometer in the wave length range (200 to 900$) \mathrm{nm}$, resulting in a decrease of the absorbance at $560 \mathrm{~nm}$ band peak with increasing dose. Regarding to the IR transmittance it's appearing that for the samples with crystal violet the band at 1716 divided two small bands which become obvious for the irradiated one which indicate also the effect of gamma doses. In this study, the less Full Width at Half Maximum (FWHM), the better is the dosimeter. The FWHM due to sharpness in the band peak and this is useful for determine the fine dosimeter.
\end{abstract}

Keywords: Irradiation; Dyes; Plastic; Polyvinyl Alcohol; Dosimeter; FWHM

\section{Introduction}

Dosimetry plays an important role in the quality control of radiation processing [1]. Many film dosimeters are used for radiation dosimetry such as radiochromic plastic films of various types and some polymers [2]. PVA based films are easy to make and thus, amenable for largescale production and application for routine irradiation processes of food and medical equipment's [3]. The induced colour bleaching of organic dyes under gamma irradiation has been reported by some researchers $[1,4,5]$. For routine dose monitoring in radiation processing, the polymeric dyed flexible films are considered to be the most common ones as dosimeters, dose labels and indicators [6].

Radiochromic thin film dosimeters have wide-spread application in radiation processing for installation and process qualification and routine dose control for both Gamma and electron irradiation. The applicability of label dosimeters is of imported fruits and nuts $[7,8]$.

In general studies it's appear that when dyed plastic films exposed to irradiation there are three possibilities occurred as follows:

- No response

- Bleaching

\section{- Color changes}

\section{Materials and Methods}

The film samples of the polymer, carbol fuchsin and crystal violet (which abbreviated as $\mathrm{CV}, \mathrm{CF}$ and PVA respectively) were prepared by using a solvent casting method. The PVA polymer powders $\left(\mathrm{M}_{\mathrm{w}} 125000\right.$, purity $98 \%$, obtained from Goumhouria Co., Egypt). The polymer was dissolved in double distilled water at $90^{\circ} \mathrm{C}$ and cooled at room temperature. CF dye is a mixture of phenol and basic fuchsin, used in bacterial staining procedures CF structure shown in Figure $1\left[\mathrm{C}_{17} \mathrm{H}_{19} \mathrm{NHCL} \mathrm{M}_{\mathrm{w}}\right.$ obtained from Sigma] were added to the polymer solution, every $10 \mathrm{ml}$ PVA added to $5 \mathrm{ml} \mathrm{CF}$ and added to this solution $0.5 \mathrm{ml}$ from $\mathrm{CV}\left[\mathbf{C}_{25} \mathbf{H}_{30} \mathbf{C l N}_{3}\right]$ and its structure shown in Figure 2. Another films $10 \mathrm{ml} \mathrm{PVA}$ added to 5 $\mathrm{ml} \mathrm{CF}$ wait stirrer for $24 \mathrm{~h}$ to obtain homogenous solution. Casting the solutions and leave it to dry for $72 \mathrm{~h}$ at room temperature.

\section{Irradiation and Measurement}

PVA films where cut in the size $1.2 \times 1.2 \mathrm{~cm}^{2}$ which is suitable for irradiation and for spectrophotometric meas 
<smiles>Cc1cc(C(=C2C=CC(=N)C=C2)c2ccc(N)c(C)c2)ccc1N</smiles>

Figure 1. Carbol fuchsin structure.<smiles>CN(C)c1ccc([C](c2ccc(N(C)C)cc2)c2ccc(N(C)C)cc2)cc1</smiles>

Figure 2. Crystal violet structure.

urements (film holder). This films where irradiation in the central position of cobalt-60, $20 \times 20 \mathrm{~cm}$ located at Oncology department Al-Kasr Alini hospital-Egypt. The films set in the phantom at depth $4.4 \mathrm{~cm}$ Perspex (tissue equivalent) $\cong 5 \mathrm{~cm}$ in water, the distance between source and skin sample SSD $=80 \mathrm{~cm}$ (The source to surface distance) $\mathrm{d}=$ depth $=5 \mathrm{~cm}$.

Using a standard geometry to minimize the errors introduced during irradiation dose rate of gamma source was $133.6 \mathrm{~Gy} / \mathrm{hr}$. Films were exposed to different doses $(10,20,30,40,50,60$ and 70$)$ Gy at room temperature. The thickness of the films was measured at 5 randomly selected places with thickness gauge having an accuracy of $\pm 1 \mathrm{~m}$. The average thickness of the films was found to be $0.04 \pm 0.06 \mathrm{~mm}$. The absorption spectra of the unirradiated and irradiated films were measured in the wavelength range 200 - $900 \mathrm{~nm}$ using Evolution $600 \mathrm{UV}-\mathrm{V}$ is spectrophotometer.

\section{Results and Discussion}

\section{Absorption Spectra}

In the current work, dyed films of poly(vinyl alcohol) prepared by casting aqueous solutions of PVA containing carbol fuchsin and crystal violet on glass plate, are investigated to be used as dosimeters for radiation processing. These flexible plastic film dosimeters $((\mathrm{CF}+\mathrm{CV}) / \mathrm{PVA})$ are bleached when exposed to gamma ray photons. The absorption spectrum of the unirradiated and irradiated films shows a main absorption band in the visible region peaking at $560 \mathrm{~nm}$ (Figures 3 and 4).

The dose-response functions in terms of net absorbance change, $\left(\triangle \mathrm{A}=A_{0}-A_{i}\right)$, as a function of absorbed dose, where $A_{o}$ and $A_{i}$ are the absorbance's at $560 \mathrm{~nm}$ of the unirradiated and irradiated $((\mathrm{CF}+\mathrm{CV}) / \mathrm{PVA})$ films are shown in Figure 5. From this figure it can be seen that the figure is linear for all the dose range, so this dose range can choose to be a useful dose range for this dosimeter. It can be seen from Figures 3 and $\mathbf{4}$ that the bleaching occur but the degree of bleaching for the films containing $\mathrm{CV}+\mathrm{CF}$ is less than the films containing $\mathrm{CF}$ only by $10 \%$ comparing the first dose and the last dose for the two systems, this will be investigated in a large scale in the next paragraph.

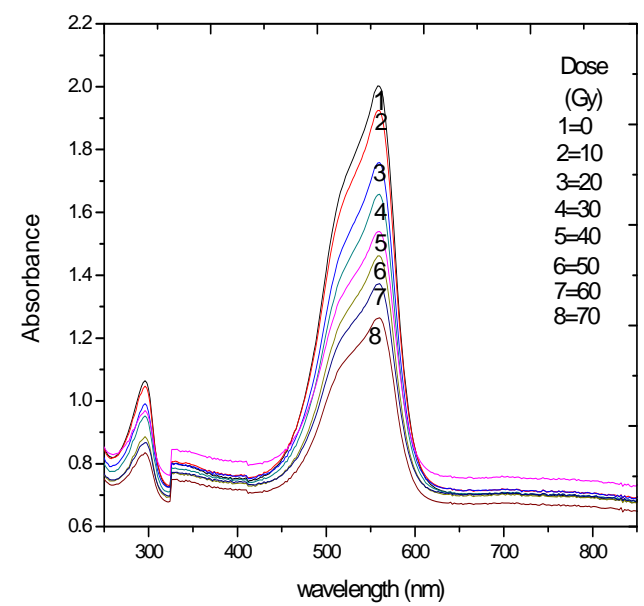

Figure 3. UV/Vis spectra of polyvinyl alcohol + CF films for concentration $5 \mathrm{ml}$ at different gamma doses $(0,10,20,30$, 40, 50, 60 and 70) Gy.

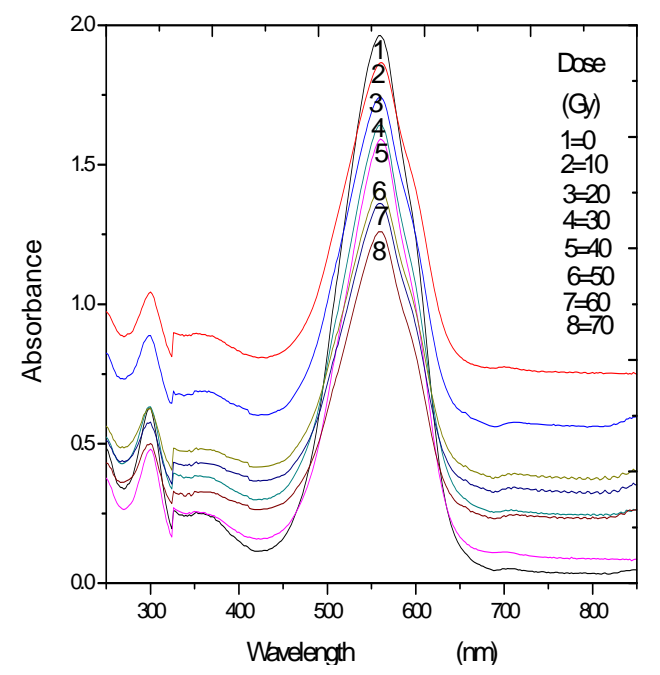

Figure 4. UV/Vis spectra of polyvinyl alcohol + (CF/Crystal Violet) films. Irradiated by gamma rays at different doses $(0,10,20,30,40,50,60$ and 70$) \mathrm{Gy}$. 


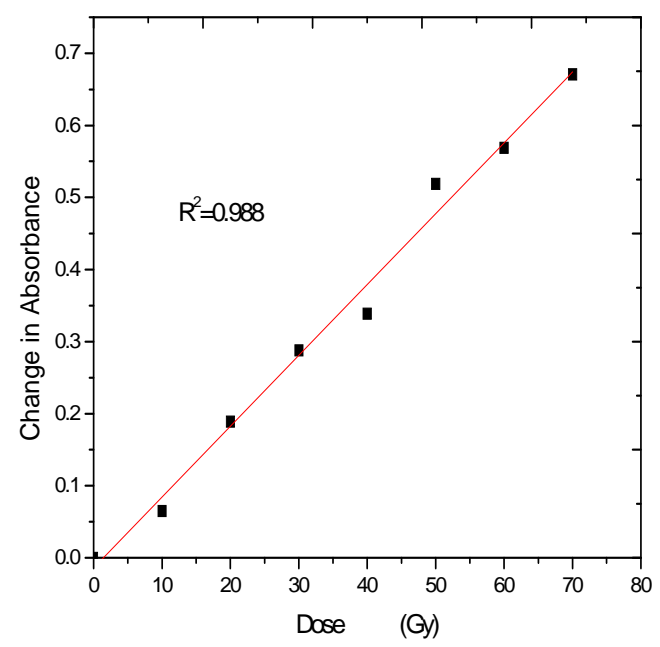

Figure 5. Plot of absorbance of (CF + CV)PVA film at $\lambda=$ $560 \mathrm{~nm}$ versus $\gamma$-irradiation dose in $\mathrm{Gy}$.

\section{FWHM for PVA/CF and (PVA/CF + CV)}

Figure 6 shows the full width at half maximum (FWHM) for PVA $(\mathrm{CF})$ and PVA $(\mathrm{CF}+\mathrm{CV})$ with different gamma doses all data are estimated by using origin pro 8 program and the data obtained from UV spectra. We study the behavior of the band at $560 \mathrm{~nm}$ at different doses for the blended films and estimate the FWHM. It appears from Figures $\mathbf{3}$ and $\mathbf{4}$ that when the films exposed to different doses the color of the films gradually bleaching we can not see the color with naked eye. In this case it can be used the variation of FWHM as inference group to different absorbed doses in range (0 to $70 \mathrm{~Gy})$, for example when exposure some films to different doses and the calculation of the FWHM of each and hence alone can determine which films exposed to high or low doses. FWHM is the way to determine the difference between absorbed doses, but was unable to determine the amount of dose. FWHM in case of carbol fuchsin is $(104,95,90$ $\mathrm{nm})$ at $560 \mathrm{~nm}$ according to $(30,50,70 \mathrm{~Gy})$ respectively and FWHM in case carbol fuchsin with Crystal Violet is $(80,78,62 \mathrm{~nm})$ at $560 \mathrm{~nm}$ according to $(30,50,70 \mathrm{~Gy})$ respectively. We noticed in the previous section that the FWHM in the Case CF + CV films less than FWHM in the Case CF only; this is improvement to the situation of the curve. FWHM depend on absorbed dose, the narrow FWHM gives the best peak this is due to Accuracy in determining the wavelength, so the addition of crystal violet play an important role for this dosimeter in which it decrease the bleaching rate of the dosimeter and increase its stability.

\section{FT-IR for PVA/CF and (PVA/CF + CV)}

Figure 7 shows the IR for the unirradiated and irradiated films and study the change of the addition of the crystal violet to these films, these changes are mainly represented

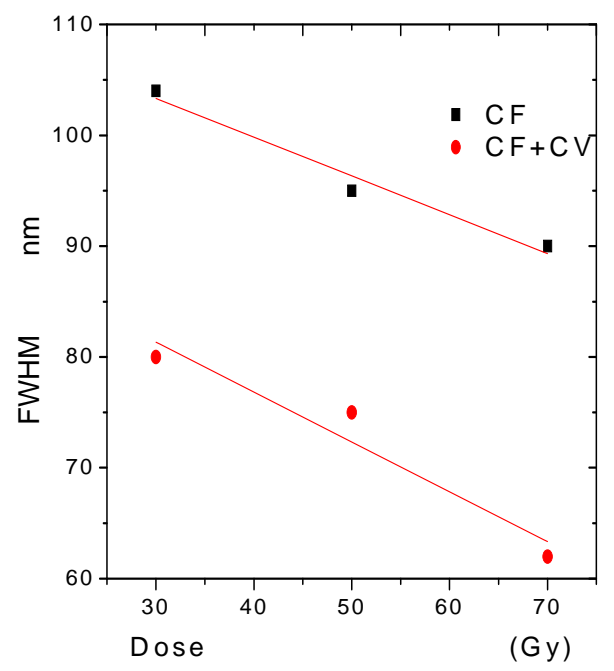

Figure 6. FWHM at 30, 40, 50 Gy for PVA + CF and PVA + (CF + CV) films.

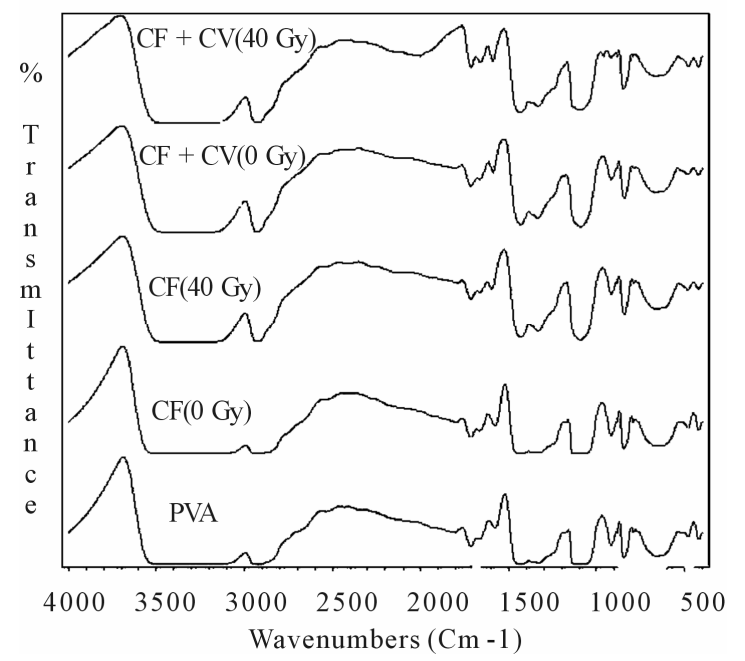

Figure 7. FTIR for unirradiated and irradiated films.

by the appearance of three absorption bands, the first at about $3500 \mathrm{~cm}^{-1}$ which is attributed to the formation of $-\mathrm{OH}$ groups, the second at $1716 \mathrm{~cm}^{-1}$ which is attributed to the stretching vibration of ketonic carbonyl groups and the third at $1180 \mathrm{~cm}^{-1}$ which is probably due to the $-\mathrm{C}-\mathrm{O}-$ absorption of the peroxide cross-links $[9,10]$.

It appears the effects of the addiation of crystal violet to the original films which indicates that the important role for that dye in which its increase the stability of the films which lead to the stretching or sharpness of the band as shown in Figure 5. From the IR transmittance figure it appears that for the samples with crystal violet the band at $960 \mathrm{~cm}^{-1}$ the divided two small bands which become obvious for the irradiated one which indicate also the effect of gamma doses. The broadening at 1816 $\mathrm{cm}^{-1}$ also reflects the effect of gamma and crystal violet for the host polymer. 


\section{Conclusion}

In this study, the poly vinyl alcohol based films containing carbol fuchsin and crystal violet dyes after irradiation with gamma raye that radiation induced bletching of these films can be used for dosimetry when this films exposed to accumulated doses from (10 to $70 \mathrm{~Gy}$ ) in wave length range (200 to 900) showed an absorption band at $560 \mathrm{~nm}$. The fitting of the dose-response curves $\mathrm{y}=\mathrm{ax}+$ $b$ resulted in a linear relationship between dose and net absorbance change. The full width at half maximum (FWHM) in two films which decreased with increasing doses due to sharpness in the band peak. The FWHM can be used to determine any films exposed to high doses and it is used for determining the better dosimeter. Smaller FWHM value resolution enables the system to more clearly separate the peaks within a spectrum.

\section{REFERENCES}

[1] W. L. McLaughlin, A. W. Boyd, K. H. Chadwick, J. C. McDonald and A. Miller, "Dosimetry for Radiation Processing," Taylor \& Francis, New York, 1989.

[2] M. Kattan, Y. Daher and H. Alkassiri, "A High-Dose Dosimeter-Based Polyvinyl Chloride Dyed with Malachite Green," Radiation Physics and Chemistry, Vol. 76, No. 7, 1989, pp. 1195-1199. doi:10.1016/j.radphyschem.2006.12.004

[3] N. V. Bhat, M. M. Nate, R. M. Bhat and B. C. Bhatt, "Effect of Gamma Radiation on PVA Films Doped with Some Dyes and Their Use in Dosimetric Studies," Indian Journal of Pure \& Applied physics, Vol. 45, No. 6, 2007, pp. 545-548.

[4] W. L. McLaughlin, N. W. Holm and R. J. Berry, "Films, Dyes and Photographic Systems, Manual on Radiation Dosimetry," Marcel Decker, New York, 1970.

[5] A. Miller, "Dosimetry for Radiation Processing," Radiation Physics and Chemistry, Vol. 28, No. 5-6, 1986, p. 321.

[6] S. Ebraheem, W. B. Beshir and S. Eid, "Investigation of Dyed Film Based on 2,6Dichlorophenol-Indophenol Dyed Poly (Vinyl Alcohol) and Poly (Vinyl Butyral) for Possible Use in High-Dose Processing Dosimetry," Arab Journal of Nuclear Science and Applications, Vol. 38, No. 1, 2005, p. 1.

[7] S. Ebraheem, W. B. Beshir, S. Eid and A. Kovacs, "Spectrophotometric Readout for an Alanine Dosimeter for Food Irradiation Applications," Radiation Physics and Chemistry, Vol. 67, No. 3-4, 2003, pp. 569-573. doi:10.1016/S0969-806X(03)00107-5

[8] S. Ebraheem, S. Eid and A. Kovacs, "A New Dyed Poly (Vinyl Alcohol) Film for High-Dose Applications," Radiation Physics and Chemistry, Vol. 63, No. 3-6, 2002, pp. 807-811. doi:10.1016/S0969-806X(01)00663-6

[9] D. J. Carlsson, C. J. Dobbin and D. M. Wiles, "Direct Observations of Macroperoxy Radical Propagation and Termination by Electron Spin Resonance and Infrared," Macromolecules, Vol. 18, No. 10, 1985, p. 2092. doi: $10.1021 / \mathrm{ma} 00152 \mathrm{a} 053$

[10] J. Lacoste, D. V. Aillant and D. J. Carlsson, "Gamma, Photo and Thermally Initiated Oxidation of Isotactic Polypropylene," Journal of Polymer Science and Part A: Polymer Chemistry, Vol. 31, No. 3, 1993, p. 715. 